\title{
A Study of Opportunities and Obstacles of Social Media Uses in Contemporary PR Practices: Call to Cautious Celebration of the Benefits of New Technologies
}

\author{
Ülfet Kutoğlu Kuruç \\ Eastern Mediterranean University, Faculty of Communication \& Media Studies, Deptartment of Public Relations \\ $\&$ Advertising \\ ulfet.kutoglu@emu.edu.tr
}

\section{Baruck Opiyo}

Eastern Mediterranean University, Faculty of Communication \& Media Studies, Deptartment of Public Relations $\&$ Advertising

baruck.opiyo@emu.edu.tr

\begin{abstract}
This paper traces and documents the opportunities and potentials that social media offer PR practitioners while also highlighting peculiar challenges that such uses present to contemporary PR practitioners due, mainly - and paradoxically - to their widespread availability and usage by both PR and non PR actors. While proliferation of information, availability of modern technologies and availability of training of practitioners have greatly raised and shaped the profile of PR practice in recent decades, increase in the number of actors who are neither trained nor committed to the ethics of PR practice have posed special challenges and posed problems to the field. The mushrooming of technologies available to PR practitioners in the recent past prompts the need to rethink, re-evaluate, revisit with a view to re-assesing not only the promises that these advances bring to the practice but also the special problems that the new scenario may present to PR academics and practitioners alike. This is the exercise we attempt in this paper. There is no gainsaying the benefits of the largely direct and unfettered communication for the PR practitioners; immediate, democratic and participatory being just a few of them. However, in spite of their many benefits,, the uses of social media by PR practitioners is not free of drawbacks and threats, especially (but not solely) because of the scope they provide for abusive use. The same social networking and microblogging sites that have provided trained PR practitioners with platforms to conduct highly effective and ethical communication practices have similarly turned and empowered millions of people with smartphones and internet connection into an army of 'Journalists' \& PR practitioners without formal training or commitment to ethical principles of communication; a scenario that provides much room for reckless and irresponsible usage of these platforms where everyone is free to speak "what's on their mind." An apt way to describe the resulting complications of PR practices under this milieu may be summed by the old adage attributed to American humorist, Mark Twain that, "A lie can travel halfway around the world while the truth is putting on its shoes." Indeed, PR practitioners often find themselves resorting to fire-fighting and reactionary PR techniques in response to online uploads from a variety of unconventional sources. Thus, while conventional wisdom may readily celebrate the many virtues of social media for PR practitioners highlighting the way in which they lend themselves to two-way communication between the organization and its various publics, we caution that such assessment of social media use should be examined and understood in terms of both potential and inherent constraints and risks. The study uses critical and case studies approaches together with a survey method to argue the need to re-think and reassess
\end{abstract}


our understanding of such benefits of social media without paying due attention to the challenges these developments pose to PR practitioners

\section{Introduction}

Social media have been singled out and hailed for their ability to immediately, swiftly and directly reach the many key publics PR practitioners seek to reach; free of the encumberances of selectivity and discretion of editors as gatekeepers in the conventional media. Subsequently, these media have been hailed as presenting PR practitioners with hitherto unavailable opportunities to tell their stories directly to their target publics. The Daily (if also controversial) Tweets of the US President is a case in point of how important individuals and offices have been using social media to directly engage their audiences. The emergence of new technologies available to PR practitioners in the recent years prompts the need to re-evaluate, not only the promises that these advances bring to the practice but also the special problems that the new scenario may present to PR practitioners. Digital technologies and social media have a huge impact on public relations practices. Social networks, video sharing sites, micro-blogging sites, photo sharing sites, message boards and blogs all have revolutionized the implications and usage of PR practices in our contemporary world.

This study attempts to explore possible opportunities and obstacles offered by the use of social media in PR practices. As Weiner (2002) argues "the internet provides both a sword and a shield in dealing with the media". (Theaker, 2008, p.382) Nowadays this saying applies to the use of social media in PR as well. "The effects of new technology have been to enable people to gather information from many sources and rely on their own judgements" (Theaker, 2008, p.382).

The study uses critical and case studies approaches and a survey research to elicit the potentials in social media for PR practitioners and to also document and discuss their limitations especially in terms of abuse and unethical use. Consequently, the study is divided into two natural parts; the first part concentrates on the spectrum of opportunities and benefits of social media as a tool for effective organizational communication, and the second part higlights the potential risks and likely shortcomings of social media and likely dangers inherent in technology based, and technology-driven, if somewhat also 'free for all' digital era in comminucation.

\section{Definition of social media}

Social media are "the online tools and platforms that people use to share opinions, insights, experiences and perspectives with each other. Popular social media include blogs, message boards, podcasts, wikis and vlogs" (Theaker, 2008, P.373). According to Mersham et al. (2009) in this context 'social' refers to (two-way) communication activities and 'media' refers to the platform used for such activities. Giannini (2010) further defines social media as "all sites where participants can produce, publish, control, critique, rank and interact with online content" (p. 157).

Organizations use social media platforms for a variety of reasons such as:

1. Image and reputation management

2. Maintain a dialogue between an organization and its various publics

3. The quick dissemination of information and news

4. To contribute to the promotion of brand awareness and publicity

5. To make the public aware of the social responsibility projects of the organization

6. To reduce the costs/ expenditures of the campaigns of the organizations

7. Social media platforms can be used during crisis times to maintain quick and instant messages to the public and to provide an interactive communication platform.

Indeed Coombs (2012) underlines the potential of the new media usage for crisis communication practitioners. "Now, Twitter has revolutionized how crises are managed since citizen journalists armed with smartphones and flip cameras- all tools in our 
pockets - break news" ( Meier, 2011, p. xv). Hence, we can say that social media maintain an instant and interactive communication platform in various applications of public relations as outlined above.

The dominant paradigm in public relations except for a few scholars (Kent, 2008; Valentini and Kruckeberg, 2015) suggests that using social media are good for PR practitioners because social media can contribute to the development of two-way symmetrical model between the organization and the public. Being considered as the ideal model, this model maintains a dialogue between the organization and its various publics. A good example to two-way symmetrical model could be the example of IKEA where the employees are regularly in two way communication with their customers.

\section{Case study 1: IKEA}

IKEA is using Facebook as a vital platform for corporate branding. IKEA's Facebook page is used to strengthened the social part and reputation image of the corporation. IKEA's employees are regularly in dialogue with their customers to learn what they are saying about IKEA, its products and services. Indeed Hjelm and Thall found out that "it is the brand values that relate to the social part of the IKEA brand that are co-created and strengthened". The interactive dimension "is continuously co-created as employees of IKEA talk with customers and learn from what is said, commented and suggested" (Hjelman and Thall, 2012, p.38). Hence, two-way communication will provide direct feedback for IKEA and whenever they experience a problem they will sort it out before it becomes a crisis. As we all know acting quickly is a vital point in the handling of crisis.

Social Media have an important impact on the practice of public relations since the invention of the internet. The internet indeed provided the PR practitioners with opportunities of collecting information, monitoring public opinion and engaging in twoway communication. Back in the year 1995 Warren Newman who was the ex-president of the CIPR (Chartered Institute of PR) claimed that "the internet itself is public relations". Nowadays, with the emergence of the wikis, blogs and social network sites internet is much more important for PR practitioners than before. 2015 findings of Pew Research Center revealed that "almost two thirds of American adults (65\%) use social networking sites, up from $7 \%$ when they began systematically tracking social media usage in 2005" (Patel, 2016, online source).

The National Opinion Poll (NOP) survey that is carried out as early as the year 1999 NOP survey carried out that the respondents had used the web to:

a) Search for information on a particular company(2.9 million people)

b) Read newspapers online ( 1.9 million people)

c) Locate travel information (1.9 million people)

d) Search for financial information ( 1.3 million people)

e) Shop online ( 1.3 million people)

f) search for employment (1.2 million people) (Theaker, 2008, p.353).

Gregory (as cited in Phillips 2001) mentions 3 phases of the internet that PR practitioners must take into account these are porosity, transparency and agency. Horton (2001) extended this list even further and maintained that communication on the web should have:
1. simplicity
2. timeliness
3. openness
4. definition
5. flexibility
6. individuality
7. meaning
8. measurability (Theaker, 2008, p.354). 
Websites are other important digital tool of corporate communication. As Alison Theaker mentions "websites represents a company's image and brand values online and can be used to communicate cost effectively with many audiences, when compared to other elements of the marketing mix such as advertising and printed literature" (2008, p. 355). Communication through websites is not only internal like the communication between the corporation and its customers, it involves external communication with media and all of the other stakeholders as well. In order to have effective communication and contribute to the corporation's image and reputation, the website of a company should be successful. A survey conducted by Redsquare in the UK disclosed that internet users are not satisfied when:

a) data speeds too slow

b) the layout is disorganized

c) the websites are poorly designed

d) response is slow

e) there is too much information (Theaker, 2008, pp. 355-356 )

Hence, if an organization wants to get the best out of their website and contribute to the two-way communication between the company and its stakeholders they should give importance to the above mentioned points. The internet by creating the interactivity or dialogue between various publics contributes to the excellence theory or two-way symmetrical communication. Hence, the internet provides two-way communication. Therefore, it is essential for PR practitioners to communicate through social media and to be aware of the two-way communication and excellence theory. Nowadays, because of increased access to information through the internet, transparency and accuracy especially during the times of crisis are essential. The appearance of blogs leads the era of citizen journalism where the majority of content are user generated rather than corporate generated. As a result of the two-way communication, PR practitioners are no longer in control of the messages. They are not the gatekeepers of the information. Twoway communication initiates the citizen journalism era where the corporate messages are not simply accepted without being challenged by the public.

Dejan Vercic, President of EUPRERA posits that "there can be no doubt that public relations entered the twenty-first century as one of the governing institutions of our postmodern society. Today, it holds the same status that used to be reserved for rhetoric in Ancient Greece. We have responsibilities not only to our clients and publics, but to society and our way of life as a whole". (Theaker, 2008, p. 380)

Reputation of a company on the web requires effective use of social media. Hence, the public relations practitioners should be equipped with the skills to use social media effectively to contribute to the reputation of an organization. Apple being the top brand in the top 25 brands of the year 2016 is very effective in creating an effective reputation among its stakeholders.

\section{Case Study 2: Apple}

Apple's success as a top brand can be the outcome of selling the customer's the company's belief and reputation rather than simply its services and information about its products. Apple company is using one of the social media platforms 'You Tube' to maintain the loyalty of its customers. (http://www.youtube.com/watch?V=9pohıf3sf14). Social media as you see in this case as well has had a great impact in winning the loyalty of the customers.

As early as the year 1999, Larry Weber the chief executor officer and chairperson of weber Public Relations Worldwide claimed that new technology allowed public relations practitioners to carry out two-way communication with their stakeholders (Theaker, 2008, p.382). In our contemporary world with the use and implementation of social 
media Grunig and Hunt' s ideal model of two-way symmetrical communication is practiced more by the public relations practitioners.

It could be said that the use of social media contribute to democracy. Two-way communication model (excellence model of communication) by Grunig and Hunt is a vital part of liberal democracy. As Moloney argues "if all voices who want to speak are audible to all who want to listen, this would lead to more and informed public debates. In this way, the positive effects of PR techniques might outweigh the negative" (Theaker, 2008, p.383).

\section{Theoretical Framework of the Study}

Uses and gratifications and effects model: Windahl (1981) claimed that "a merger of uses-and-gratifications and the effects tradition was overdue and proposed what he called a uses and effects model that viewed the product of the use of media content as conseffects" (Baran and Davis, 2006, p.274). Windahl's synthesis of the "uses and gratifications' and 'effects' perspectives could be one of the models of this study where we can have insights about the adoption of social media by the PR practitioners to contribute to the two-way communication in PR practices.

Innovation Diffusion Theory: According to this theory if an innovation is considered to be useful then it will be adopted. In this case social media is the useful innovation that has been used in PR practice.

\section{Survey Findings}

From the 77 students (two classes) who were taking the course PRAD 304 (Public Relations and Advertising) offered as a core course by the department of Public Relations and Advertising (Eastern Mediterranean University) in the Spring Semester of 20162017, 9 students were taking the course as a free elective from the other departments of the university. The other 68 students are from the Public Relations and Advertising department and they have been training to become PR practitioners in the near future. The following survey questions were asked to these students as part of the final assessment of the above mentioned course (PRAD 304).

1. Do you believe that using social media for PR practice has mostly "negative effects", "positive effects" or "both negative and positive effects"? Please list at least two effects for each category that you mentioned. (categories: negative, positive both negative and positive)

2. Do you believe that the social media are influencing or changing the way in which PR is practised? Briefly describe how if your answer is in the affirmative.

3. Please identify and list any three specific social media tools that you would consider important for PR practitioners

4. To what extent do you use social media as sources of news?
a. never
b. hardly ever
c. moderate (average)
d. almost always

From the 68 students who have been training to be PR professionals 5 of them did not answer the questions. Hence, only 63 students took part in this survey.

\section{Question 1}

When the future PR practitioners were asked whether they believe that using social media for PR practice has mostly 'negative effects', 'positive effects' or 'both negative and positive effects' out of the remaining 63 respondents 7 of them (approximately $11 \%)$ did not answer this question. 23 respondents (36.5\%) claimed that using social media for PR practice has mostly 'positive effects' whereas the other 33 respondents which was the majority $(52.4 \%)$ claimed that social media have 'both negative and positive effects' for the public relations practice. 


\section{Positive Effects}

When the future PR practitioners listed the positive effects the following responses were the most popular ones:

1. Social media contribute to mutual understanding and two- way communication between an organization and its publics. (23 students; $36.5 \%$ )

2. Social media disseminate messages to a large, heterogeneous audience in a short period of time ( 23 students; $36.5 \%$ )

3. Social media provide a wide platform where information can easily be communicated to the target audience (18 students; $28.5 \%$ )

4. Social media provide quick information to the public (12 students; $19 \%$ )

\section{Negative Effects}

When the future PR practitioners listed the negative effects the following responses were the most popular ones:

1. Social media by supporting the unethical use of public relations will manipulate the public (16 students; $25.3 \%$ )

2. Social media cannot be easily controlled so any false information about an organization will spread and destroy the reputation of that organization ( 7 students; $11.1 \%$ )

3. Social media may give false news to the public ( 7 students; $11.1 \%$ )

\section{Question 2}

When the future PR practitioners were asked whether they believe that the social media are influencing or changing the way in which PR is practiced 48 respondents $(76.2 \%)$ answered in the affirmative. The majority of the respondents said that social media are changing the way in which PR is practiced. Only 4 of them $(6.3 \%)$ said that social media are not changing the way in which PR is practiced while 11 respondents did not answer this question. (17.5\%)

When the future PR practitioners were asked how social media is changing the way PR is practiced they mainly suggested that:

1. It is easier to communicate through social media (14 students; $22 \%$ )

2. Social media by increasing interactivity contribute to the two-way communication between an organization and its publics (14 students; $22 \%$ )

3. Social media reach to a wide range of heterogeneous audience (10 students; $16 \%$ )

4. Social media provide quick information flow (8 students; $13 \%$ )

\section{Question 3}

When the future PR practitioners were asked to identify and list the three specific social media platforms that they would consider vital for the PR practitioners; out of the 63 respondents $23(36.5 \%)$ did not answer the question. From the 40 respondents who answered this question 36 of them (90\%) chose Facebook. The other two popular social media platforms among our participants were Twitter (27 respondents, $67.5 \%$ ) and Instagram (24 participants; 60\%) respectively. You Tube (12 participates) and Blogs (10 respondents) were other PR platforms which were popular among our future PR practitioners.

The answers that the future PR practitioners provided for this question goes parallel with Verhoeven et al.(2012) who found out that European PR practitioners perceive online communities (social networks) as the most important social media tool for PR. Same study revealed that the online videos are the second most important communication tool in the field of public relations. When we consider the impact of social network sites on PR practices Toyota's "100 Cars for Good" campaign is a good example.

\section{Case Study 3: Toyota's "100 Cars for Good"}


Toyota's corporate social responsibility campaign "100 Cars for Good" is mainly designed for social media platforms (especially the social network sites). Facebook is the main platform used by Toyota to determine which NGO's will receive a free Toyota car. The campaign was launched in the year 201land because of the success of the campaign it has been repeated in the year 2012 as well.

(http: www.toyotaglobal.com/sustainability/social_contribution/society_and_culture/over seas/100cars)

\section{Question 4}

When the future PR practitioners were asked to what extend do they use social media as sources of news out of the 63 respondents 49 of them chose 'almost always' $(77.7 \%)$ and 11 of them said that they use it 'moderate' (17.4\%). 3 respondents did not answer this question. The answers that the future PR practitioners provided revealed that the great majority of them which was $77.7 \%$ use social media 'almost always' as sources of news.

Social media maintains an effective forum for PR practitioners and publicist during election campaigns as well. Since social media have a great significance in brand making and reputation management many corporations are using social media to communicate with their publics. In our survey Facebook, Twitter and Instagram are the most popular social network sites among the future PR practitioners however the list is not only limited to these three platforms, Linkedln, Pinterest and Google+ cannot be underestimated if PR practitioners of our times would like to convey their stories effectively to their publics. When we consider the advantages of such social media platforms we find out that:

\section{Facebook}

Facebook is very popular among the masses. Facebook has billions of users daily. It is a quick way to reach to the desired publics and promoting the brands. In Facebook there are a variety of ways to reach to the audience of an organization such as posts, images, videos, links etc. To be effective in Facebook the organization needs to update their Facebook pages regularly and try to create a strong bond (two-way communication) with their audience. Facebook is an effective social media platform to provide mutual communication environment.

\section{Twitter}

Twitter is another popular social network sites of our times for PR practitioners. In twitter there is a character limitation ( 140 characters). Hence the message that you want to give should be brief and effective. Twitter is good especially for making announcements to the public about an upcoming event like a press conference, introducing a new product or service or informing an organization's audience about a recent crisis. Twitter provides a platform where one can create brand awareness in the social media community.

\section{Instagram}

Instagram is another popular platform for PR practitioners. It is an easy source to follow news. In Instagram the visual image is more important than the written text. One of the most important benefits of this platform is to use visuals to create awareness about issues, cases, services and products.

\section{Google+}

PR practitioners can use this popular platform to reach to their target audience easily. Google+ ensures that the corporation will reach to its stakeholders when they want to send them information that they will be looking forward. Google+ is an ideal platform to circulate press and media releases, announcements, recent campaigns and current news. 


\section{LinkedIn}

Linkedln is another popular SNS for PR practitioners. PR practitioners can use this platform to disseminate news and campaigns, connecting with new clients, discovering the various press and media opportunities. Organizations can create free polls and share them through Linkedl $n$ to get feedback from the stakeholders based on a service or product. Linkedln helps you to improve the reputation of your organization's profile.

However the use of the appropriate social media platform is not enough. In order to have effective campaigns the organizations need to have prepared and planned PR strategies as well. Moreover, you should make it easy for your audience to reach to a specific web page to carry out the intended actions that you want to implement. Low cost advertisements in social media like Facebook, Linkedln or YouTube will make the organizations to cut down the expenditures and carry out cheaper campaigns. The organizations try to keep their dialogue with their audience by creating bond with their stakeholders and to carry out two-way communication to get constant feedback from their stakeholders. Doing this will help the organizations to improve their reputations.

Social media maintains an effective forum for PR practitioners and publicist during election campaigns as well.

\section{Case Study 4: Obama's Election Campaigns in US}

US president Barack Obama used social media excessively both in the 2008 and 2012 elections. In 2012 presidential elections in the US Barack Obama defeated his rival and became the president of America for the second time. When we compare Obama's use of social media with his rival Romney we found out that:

In October 2012 "President Obama had over 20 million followers on Twitter and Romney had 1.2 million On Facebook Obama had over 29 million likes on his page and Romney had 7.9 million On Instagram Obama had 1.4 million followers and Romney had 38.000 Obama has more followers in the other social media platforms like You Tube and Pinterest as well" (Patel, 2016, online source).

Barack Obama by using the social media platforms effectively managed to convince especially the undecided young generations and made them to vote for him. Social media nowadays are vital tool and the people who use it in the right way will get the benefit out of it.

\section{Social media are good, social media are bad!; let every PR practitioner beware !} Causes for cautious optimism

The second part of this paper focuses on the downside of social media and new technologies, and delves into issues that practitioners may need to guard against. The discussions revolve around issues best summed up by a quote attributed to American humorist Mark Twain (1835-1910) regarding the truth. "A lie can travel halfway around the world while the truth is putting on its shoes," he said. The practice of public relations have long revolved around public opinion, understanding, and reputation - all for which truth is pertinent.

In the preceding pages we have reviewed literature, highlighted three cases and delved into discussions to demonstrate the enormous potential that social media possess for PR practitioners in private sector organizations, NGOs, governments and individual users of social media. We argued so based on the fact that these media, unlike the conventional media, enable practitioners to engage their various audiences directly, unfiltered, and fast. Notwithstanding these advantages and benefits of social media, we wish to caution against excessive or misguided celebration by PR practitioners; it's imperative that PR practitioners and academics remember (at least) two key concerns. First is that as PR has steadily grown in the past, ethics steadily grew to play an important role as one of the pillars of professional PR practice. And second is that PR education and training 
similarly grew as another pillar that helped infuse professionalization into the practice catapulting PR to the professional pedestal on which it arguably stands today. The two, together are what have helped to maintain integrity and professionalism in PR in the age where cutthroat competition among and conflict within organizations could well bring real temptation to revert to the practices of the early days when propaganda, outright lies such as pseudo-events were widely used to gain publicity and visibility for organizations through the press agentry model (Baskin, et all, 1997; Wilcox, et al. 2011). It's almost universally the case that all Associations of PR professionals such as Public Relations Society of America (PRSA), International Public Relations Association (IPRA) and other such bodies have codes of ethics governing professional behavior of their members. This, together with training of practitioners in Universities at undergraduate and postgraduate levels is what has helped professionalize - and infused excellence into the practice in recent decades.

New communication technologies and the social media, although democratic and helpful in expediting and democratizing two-way communication for practitioners, have also brought some new challenges of their own which are worth paying attention to. A handful case studies from the United States and the East African country of Kenya would adequately help illustrate this point whose applicability is, however, universal. Two key arguments are that social media users are not necessarily committed to ethical practices in their use, and that social media have turned an army of people into 'Journalists' armed with technological devices but without training - a potent and dangerous combination leading to disastrous and potentially explosive consequences for both practitioners and general public alike where the line between truth, reality and what is increasingly referred to as "fake news" is blurred and fast disappearing. Consequences are both challenging and potentially dire for the profession and academia as many good lies continue to travel half way around the world before PR practitioners armed with the truth have put on shoes.

\section{Case Study 1: Facebook and alleged Russian interference in the US elections}

\section{facebook}

Allegation: Since the presidential elections in the US in November 2016, there have been protracted debates regarding whether Russia had a 'preferred candidate' and successfully and electronically managed to influence the outcome of the elections. Only last month it was established that ten million Americans were exposed to $\$ 100,000$ advertisements placed by Russian State operative known by the name "Internet Research Agency," apparently with the intention to influence the outcome of US presidential elections in favor of eventual winner Donald Trump. Facebook has since acknowledged that about 10 million Americans saw Russian-linked ads on Facebook, prompting the company to place full place adverts in both the New York Times and Washington Post newspapers to outline the "immediate actions" Facebook will take to "fight any attempt to interfere with elections or civic engagement on Facebook." Last month (September 2017), Facebook said that nearly 500 accounts that likely came from Russia bought $\$ 100,000$ of Facebook ads during the election. What is interesting - and significant is that the nine measures spelt out by Facebook appear to indicate that, their system was compromised via technology, and that even people at Facebook themselves were unaware at the time. Among the things Facebook highlighted as "immediate actions they would take" included:

\section{Making advertising more transparent}

We are building new tools that will allow you to see the ads a Facebook Page is running, including ads that aren't targeted to you directly.

\section{...3. Investing in security}


We will more than double the team working to prevent election interference on Facebook and develop new technologies dedicated to security and safety (implying weaknesses may have been detected).

\section{Sharing the ads we've found with Congress}

We shared more than 3,000 ads that appear to have come from a Russian entity known as the Internet Research Agency (apparently to pre-empt punitive regulatory steps by US Congress).

\section{Continuing our internal investigation}

We are working to further our understanding of how foreign groups may have misused Facebook in order to prevent further abuse (suggesting perhaps, that more revelations would come in the future?)

\section{Fighting threats across the internet}

We recognize this is a global, industry-wide problem so we are sharing threat information with other companies. Any actor trying to misuse Facebook is likely trying to abuse other internet platforms and we need to work together (an obvious acknowledgement of existence of "threats" in the Internet).

\section{Expanding our partnerships with election commissions}

We are working with election commissions around the word to proactively communicate online risks we've identified (conceding that online risks have been identified).

\section{Supporting elections globally}

We have been actively working to help protect the integrity of elections on Facebook around the world (indicating the problem could not have been just confined to the US and Russia; a number of European countries have been targeted and have complained. Even without getting into all the details of this ongoing investigation, it does help indicate the risks and enormity of problems embedded in the social media and new technology.

\section{Case Study 2: Independent Electoral \& Boundaries Commission (IEBC- Kenya); flaws of new technology}

Like the US in November 2016, the East African nation of Kenya had a general election on August 8, 2017 to choose a President among others. The election was held under the stewardship of the country's Independent Electoral \& Boundaries Commission (IEBC). Soon after the results were declared a petition challenging them was filed in the country's Supreme Court which on September 1 nullified the results. Grounds for annulment of results were given as: Illegalities, Irregularities in the tallying and transmission of transmission of results (due mainly to alleged malpractices by a French IT firm contracted by IEBC), among other things. It was later alleged that technology was used (or misused) to manipulate numbers to come up with what the Opposition activists referred to as "Computer generated leaders." The country is tense and due for a repeat election as we write this, and one of the main points of contention is fraudulent use of technology to interfere with or fabricate outcomes of the electoral process. The PR or Communication Department at IEBC has been left in a position of deafening silence as the Government and Opposition players have attempted to throw "evidence" of fraud back and forth, evidently unable to create or maintain understanding of any kind. If anything, the electoral body is probably experiencing its worst crisis and credibility gap in its history.

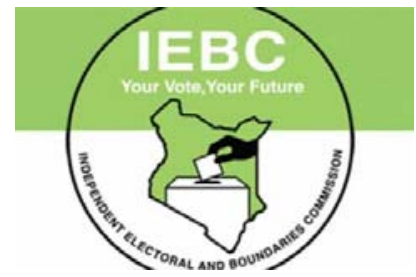




\section{Case Study 3: Leonard Mambo is dead;}

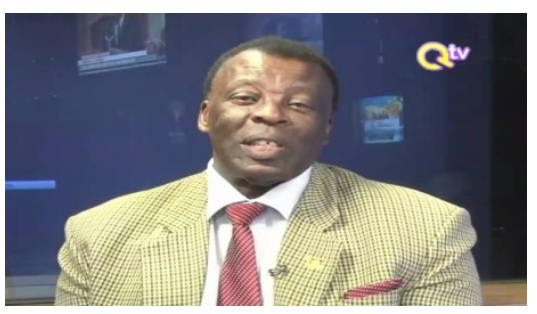

Still on the East African country, Kenya, there is a general belief that the months of July and August are junxed ones as prominent politicians coincidentally usually die during these two months. In July and August 2017 four prominent Kenyans died including the country's Minister for Internal Security who collapsed in his house. So when a popular Blogger wrote that Kenya's Veteran Kenya Broadcasting radio/TV broadcaster Leonard Mambo Mbotela had died in a road accident in July, the "news" travelled around the world within minutes only for Mr Mambo who shot into fame through his radio programme "je huu ni ungwana?" to assure his fans a day later that he was actually not dead, and was in actual fact, relaxing at home when the news about his death started travelling all over the world. Mr Mambo's supposed death was a talking point in social media platforms on Saturday (July 29, 2017) morning after people started a rumour that he was the latest victim of the Grim Reaper that seems to be working on overdrive this July, with four prominent personalities having died in a span of two weeks. "I am alive and well. I have received more than 90 calls and many messages since morning of people trying to find out if I was indeed alive. My family members at the coast are deeply distressed. I am even told one of them fainted on hearing the news," said $\mathrm{Mr}$ Mbotela. Although this may sound humorous it does help make the point of the potential for misuse and abuse that the social media and new technology have placed in the hands of most. Mr Mambo could be substituted by a product, a rival company, an opponent in a race or any factually accurate information being "killed" and replaced or substituted by deliberate or accidental misinformation which in the era of immediacy and speed provided by the new technologies present a nightmare scenario for PR practitioners, bearing in mind remedia action (image repair) is never as easy as the initial causing of damage through malicious or accidental spread of lies or bad news. These three cases are but a small sample of the many salient dangers in the web, the social media and by extension generally of new communication technologies which although offer many opportunities for PR practitioners have many inherent problems, compounded by their availability to amateur, seasoned, ethical and unethical users alike.

\section{Summary, Conclusions and Recommendations}

In this paper we've attempted to explore and enumerate the many special opportunities and benefits that social and new media along with new (and largely mobile) technologies have accorded PR practitioners in the recent past. While doing so we've argued that these fairly new opportunities can and have enhanced both the actual and potential impact of public relations in the corporate sector, government and non-governmental sectors all around the world. We have also sounded a two-pronged alarm regarding what we feel PR practitioners and scholars ought to do in the context of the new developments. These include but are not limited to: a). The need to equip existing and emerging PR practitioners with requisite skills that would enable them cope with the new advances in technology and widely documented emerging shift to the usage (as well as influence and dominance of) social media as the preferred sources of information for most people in modern society. This would enable PR practitioners to be more up to date in what they are able to do with and gains they can derive from using such new technologies. As a result, the impact of PR on organizational communication practices incorporating the newly-availed technologies and new media platforms will have greater 
impact and effect. We've further argued that such empowerment of PR practitioners could take at least two forms - both of which are critical and necessary; one could be through ongoing and on the job new media mastery training of practitioners to enable them master and adapt to the usage of a variety of new technologies in a rapidly changing and technology-driven environment, so as to be able to let the use of these very technologies anchor their PR practice agenda. Given the current trends, mastery of social media skills is not a luxury or optional to PR practitioners but a necessity.

b). Our second and more formal proposal is for institutions of higher learning like Universities which have PR programs to update their curriculum to incorporate courses that deal with both theoretical as well as practical aspects of social media. This would enable those graduating from such programs to be enlightened, current and equipped to appreciate the theoretical importance of the new and social media as well as be able to effectively use them to maximize their impact on PR practices by organizations.

The study is done without overlooking the need to understand the embedded dangers and risks that might come with these new technological advances for both budding and accomplished PR practitioners. We used a case study approach to highlight just a few of these dangers which include the opening of a Pandora's box for unethical practices by non-professional actors with access to social media and/or new technologies. Skillful use of social media by crafty entities who do not feel bound by conventional (nay, professional) PR ethics have led to the problems that range from fake news intended to sway public opinion in certain pre-determined directions, to placing PR and advertising messages in unsuspecting and not so tightly regulated social media - leading to controversies that on the mild side include propagation of false information, and on the extreme side may lead to the election of 'wrong' candidates for important elective political offices in different parts of the world, including some of the most influential ones. The twin scope for effective use as well as provision for abuse clearly demonstrate how new communication technologies and social media are akin to a doubled-barelled gun in the hands of practitioners and others that could be used to either protect or destroy, depending on how it is used or who uses it. We conclude by saying that since advances in technology are only going to increase with time, PR practitioners and academics need to do everything to ensure they stay ahead of the pack through vigilance, ongoing dialogue and engagement by the like-minded, and increased training and updating of PR curricula in Universities to strengthen professional, ethical practices. While writing to define and defend what they consider Journalism's first obligation as "Obligation to the truth," Kovach and Rosentiel (2001) wrote: "Over the last three hundred years, news professionals have developed a largely unwritten code of principles and values to fulfil the function of providing news - the indirect knowledge by which people come to form their opinions about the world. Foremost among these principles is this: Journalism's first obligation is to the truth." (p. 37). No less can be said about public relations, especially in the context of the many threats that confront the profession in the era of new communication technologies and the social media. The journey of 1000 miles begin with one step, said the Chinese. Let that be our first collective step in October 2017.

\section{References}

Apple's case: (http://www.youtube.com/watch?V=9pohıf3sf14).

Baran, S. J. \& Davis D. K. (2006). Mass Communication Theory: Foundations, Ferment and Future ( $4^{\text {th }}$ Edition). Australia, Thomson Wadsworth.

Baskin, O., Arnoff, C. \& Lattimore, D. (1997). (4 ${ }^{\text {th }}$ Ed.). Public Relations: The Profession $\&$ the Practice. Boston, MA: McGraw-Hill.

Coombs, W. T. (2012). Ongoing crisis communication: Planning, managing, and responding ( $3^{\text {rd }}$ Ed.). Thousand Oaks, CA: Sage.

Giannini, G. T. (2010) Marketing public relations: a marketer's approach to public relations. Upper Saddle River, NJ . 
Gregory, A. (1996). Planning and Managing a Public Relations Campaign. Kogan Page/ IPR.

Grunig, J. \& Hunt, T. (1984). Managing Public Relations, London: Holt, Rinehart, \& Wiston.

Hjelm Y. H. \& Thall, S. S. (2012). Facebook as a platform for corporate branding: How IKEA brand values are co-created in communication by users on Facebook, Online Bachelor thesis within the Media and Communication Science, School of Education and Communication, Jönköping University. http://www.divaportal.org/smash/get/diva2:504689/fulltext01

Holtz, S. (1998). Public Relations on the Net. Amacom.

Horton, J. L. (2001). Online Public Relations. Quorum Books.

Jefkins, F. (2001) (6 $6^{\text {th }}$ Ed.) Public Relations. Harlow, England: Financial Times Prentice Hall

Jordan-Meier, J. (2011). The Four Stages of Highly Effective Crisis Management: How to Manage the Media in the Digital Age, Taylor \& Francis Group.

Kent, M.L. (2008). Critical analysis of blogging in public relations. Public Relations Review, 34(1), 32-40. http://dx.doi.org/10.1016/j.pubrev.2007.12.001

Kovach, B. \& Rosentiel, T. (2001). The Elements of Journalism: What Newspeople Should Know and the Public Should Expect. New York, NY: Three Rivers Press.

Mersham, G., Theunissen, P., \& Peart, J. (2009) Public Relations and Communication Management: an Aoteroa/ New Zealand Perspective. Auckland, NZ: Pearson.

Moloney, K. (2006a). Rethinking Public Relations: PR , Propaganda and Democracy. London, Routledge.

Newman, W. (1995). Community Relations in N. A. Hart (ed.) Strategic Public Relations.

MacmillanPatel, T. (2016). The Role and Influence of Social Media on the Modern PR Industry. http://www. prmention.com/blog/the-role-and-influence- of-social-mediaon-the-modern-pr-industry/

Phillips, D. (2001). Online Public Relations. Kogan Page.

Theaker, A. (2008). The Public Relations Handbook ( $3^{\text {rd }}$ Edition). New York, NY: Routledge.

Toyota'sCase: (http:www.toyotaglobal.com/sustainability/social_contribution/society_an d_culture/overseas /100cars)

Valentini, C., \& Kruckeberg, D. (2015). The future role of social media in international crisis communication. In M. Löffelholz, A. Schwarz \& M. Seeger (Eds.), The handbook of international crisis communication research. UK, Wiley-Blackwell.

Valentini, C. (2015). Is using social media "good" for the public relations profession? A critical reflection. Public Relations Review, 41, 170-

177. http://dx.doi.org/10.1016/j.pubrev.2014.11.009

Verhoeven, P., Tench, R., Zerfass, A., Moreno, A., \& Vercic, D. (2012). How European PR practitioners handle digital and social media. Public Relations Review, 38(1), 162-164. http://dx.doi.org/10.1016/j. pubrev.2011.08.015

Waweru, T. (2017). Fake News: NASA planted bomb on SusanKihika's helicopter that crashed into Lake Nakuru. Retrieved from:

https://www.standardmedia.co.ke/article/2001258109/fake- news-nasa- plantedbomb-on-susan-kihika-s-helicopter-that-crashed-into-lake-nakuru on October 23, 2017

Weiner, M. (2002). A forward look at Public Relations, The Public Relations Strategist, Spring pp.32-35.

Wilcox, D.L., Cameron, G.T., Reber, B.H., \& Shin, J. (2011). Think Public Relations. Boston, MA: Allyn \& Bacon

Windahl, S. (1981). Uses and Gratifications at the Crossroads. In G. C. Wilhoit and H. De Bock, Eds., Mass Communication Review Yearbook. Beverly Hills, CA: Sage. 